\title{
Los jóvenes internados en prisiones andaluzas. Sus actitudes ante los procesos de reeducación
}

\author{
Víctor Manuel Martín Solbes \\ UNIVERSIDAd de Málaga
}

\section{Resumen}

Los procesos de reeducación constituyen una de las finalidades de la Institución Penitenciaria. Pero estos procesos proporcionados por la Institución deben ser recibidos por las personas internadas en prisión de manera eficaz y activa, por lo que es necesario que estas personas mantengan una actitud adecuada. Ante esta situación, parece oportuno conocer las actitudes de las personas presas ante los procesos de reeducación.

PALABRAS CLAVE: reeducación, actitud, prisión, jóvenes.

\section{Summary}

The reeducation processes constitute one of de purposes of de Penitentiary Institution. But these processes provided by the Institution must be received by the people inmate in prison of effective way and activates, reason why it is necessary that these people maintain an attitude suitable. Before this situation, it seems opportune to know the attitudes the imprisoned people before the reeducation processes.

KEY WORD: reeducation, attitude, prison, young people.

\section{Introducción}

Con este artículo tratamos de sintetizar una investigación con la que pretendíamos conocer las actitudes de los jóvenes menores de veintiún años internados en los centros penitenciarios andaluces, ante la función reeducadora de la Institución Penitenciaria. Para llegar a este conocimiento, nos marcamos los siguientes objetivos:

- Conocer las actitudes mantenidas por los jóvenes ante los procesos de reeducación.

- Valorar la importancia de la educación y de la formación para evitar procesos delincuenciales.

- Valorar el trabajo preventivo en el ámbito social para evitar ingresos en prisión.

- Valorar la importancia del tiempo de ocio en prisión para evitar deterioros.

- Reconocer la importancia de la educación social en el ámbito penitenciario.

Debemos comenzar diciendo que las Instituciones Penitenciarias son instituciones problemáticas dentro de nuestra sociedad, más aún si consideramos estos lugares tradicionalmente de encierro, castigo y aislamiento social, como lugares donde se pre- 
tenden acometer procesos de reeducación y reinserción social, tal y como se indica en nuestra legislación. Así, el artículo 25.2 de la Constitución Española establece que las penas privativas de libertad deben orientarse hacia la reeducación y la reinserción social. Pero estos procesos de reeducación y de reinserción social se desarrollan dentro de un marco institucional y arquitectónico que los condicionan. Así, podemos citar como condicionantes, los siguientes:

- La gran importancia que en el marco de la política general penitenciaria tienen los aspectos regimentales de orden, seguridad y disciplina, frente a las posibles intervenciones educativas.

- El medio penitenciario, como medio institucional cerrado y voraz que dificulta la participación educativa y cultural.

- El nivel educativo y cultural de los internados, que es bastante precario.

- Las escasas ofertas educativas y socioculturales.

- La movilidad de la población internada, ya que sea por motivos de libertad o por motivos de traslado a otros centros penitenciarios, lo cierto es que la población es poco estable.

- La carencia de recursos económicos, técnicos y humanos.

- La gran pobreza en la que se mueven la gran mayoría de los internados.

- La evidente falta de libertad, que es la característica fundamental del medio penitenciario.

Además de estos condicionantes, a la hora de abordar acciones reeducadoras en el medio penitenciario, debemos tener en cuenta una serie de variables, como son:

- Variables ambientales, ya que todo se circunscribe a unas estructuras arquitectónicas orientadas a la vigilancia y a la seguridad, no a lo educativo.

- Variables regimentales, ya que el propio régimen de vida de los internos, los ho- rarios, las visitas del exterior, los traslados, las sanciones disciplinarias, suelen influir en el estado emocional de los internos de manera negativa.

- Variables psicosociales, ya que a menudo, los internados en centros penitenciarios mantienen hábitos de drogodependencias que les producen deterioros físicos y psíquicos. A lo que hay que añadir los cambios anímicos, la impotencia por no poder resolver problemas familiares desde el encierro, enfermedades, la falta de valores sociales normalizados.

- Variables personales, ya que desde el encierro, sólo pretenden, en la mayoría de los casos, acceder lo antes posible a la vida en libertad, lo que produce estados de inquietud y ansiedad que suelen dificultar la acción educativa.

Nos hemos centrado en los jóvenes menores de veintiún años internados en centros penitenciarios, basándonos en cinco criterios:

- Penitenciarios, ya que deseamos estudiar a los jóvenes en prisión, y el artículo 173 del vigente Reglamento Penitenciario Español, aprobado por Real Decreto 190/1.996 de 9 de febrero, expresa en su punto 1: "El régimen de vida de los departamentos para jóvenes se caracterizará por una acción educativa intensa. Se consideran jóvenes a los internos menores de veintiún años".

- Criminológicos, porque la etapa que va desde la infancia o preadolescencia hasta los veintiún años, corresponde a la franja más activa en la carrera delictiva de un sujeto. Es en esta etapa donde se producen más conductas antisociales, se cometen más delitos, donde el grado de reincidencia es mayor y donde se refleja un riesgo más elevado en lo que se refiere a la peligrosidad social de sus actos (Kaiser, 1988). 
- Madurativos, porque al tratarse de delincuentes jóvenes, ellos son los que van a nutrir el sistema penitenciario en los próximos años, si siguen teniendo pautas delincuenciales (Beristain, 1985).

- Pedagógicos, ya que se trata de una etapa en la que la educación puede realizar una labor reeducadora fundamental, evitando así futuros ingresos en prisión.

- Psicosociales, porque a estas edades es posible la inserción, tanto social como laboral, sin romper los esquemas de la comunidad. Ésta es una etapa de construcción de la identidad en el contexto social (García y Sancha, 1986).

Por lo tanto, no es un hecho casual el que nos centremos en esta etapa. Se trata de una cuestión de eficacia pedagógica y de rentabilidad humana de los esfuerzos sociales.

Por otra parte, tratamos de estudiar la actitud, que podemos entender como la predisposición comportamental hacia una situación dada, en nuestro caso, los procesos de reeducación.

Esta predisposición comportamental está relacionada con tres componentes:

- El afectivo, relacionada con el sentir.

- El cognitivo, relacionada con el saber.

- El conativo, relacionada con el actuar.

Consistiendo estos tres componentes en evaluaciones que realizamos de la situación. Así, las percepciones pueden ser favorables o desfavorables. Los sentimientos, positivos o negativos. La conducta de apoyo u hostil.

Creemos que la tarea reeducadora y de reinserción social no tendrá los frutos deseados si las personas a las que se dirige este esfuerzo reeducador no mantienen la actitud adecuada. Siempre, teniendo en cuenta que las actitudes predisponen a una respuesta valorativa que se manifiesta a través de los componentes afectivos, cognitivos o conativos, generando a su vez respuestas afectivas, cognitivas o comportamentales (Bolívar, 1995).

Por otro lado, con la reeducación pretendemos que las personas cambien su carácter, reconozcan y hagan suyos recursos y habilidades que propicien el bien de los demás, que no les permitan cometer delitos, ya que estos causan mal a otras personas y desprestigian la propia imagen.

Podemos afirmar que estos procesos de reeducación tienen éxito, si el joven internado comienza a comportarse de manera prosocial, lo que dignificará su propia vida y la de los de su alrededor. Esto es, a través de la reeducación, se convierte en una persona socialmente competente, ya que dispondrá de recursos y habilidades de relación social, lo que le llevará a una comunicación beneficiosa con su entorno y al desarrollo de la autonomía, la solidaridad, la responsabilidad, los conocimientos, entrando así de lleno en el terreno educativo.

La reeducación, en definitiva, debe perseguir, educar para vivir de forma personalmente satisfactoria, enriqueciéndose del contacto con los demás.

Partiendo de estos conceptos de actitud y reeducación, abordamos el estudio de las actitudes ante la reeducación de los jóvenes menores de veintiún años internados en los centros penitenciarios andaluces.

\section{Metodología y análisis}

Para llevar a cabo la investigación nos hemos centrado en los internos jóvenes de los centros penitenciarios de Sevilla, Algeciras, Málaga y Granada. Y lo hemos hecho así porque en el momento de realizar la investigación, la población internada menor de veintiún años en los centros penitenciarios andaluces, era de 334 internos, de los que 311 habitaban en los centros penitenciarios 
TABLA 1. CENTROS PENITENCIARIOS VISITADOS, NÚMERO Y PORCENTAJES DE INTERNOS

\begin{tabular}{lcccccc} 
& N español & $\%$ & N extranj. & $\%$ & N total & $\%$ \\
SEVILLA & 64 & 22,4 & 19 & 6,7 & 83 & 29,1 \\
\hline ALGECIRAS & 49 & 17,3 & 27 & 9,4 & 76 & 26,7 \\
\hline MALAGA & 42 & 14,6 & 23 & 8,2 & 65 & 22,8 \\
\hline GRANADA & 46 & 16,1 & 15 & 5,3 & 61 & 21,4 \\
\hline Total español & 201 & 70,4 & & & & 100 \\
\hline Total extranj. & & 84 & 29,6 & & 285 \\
\hline TOTAL & & & & & 100 \\
\hline
\end{tabular}

antes citados. Proponemos a estos 311 jóvenes participar en la investigación, aceptando la propuesta 285 internos que se distribuían de la manera que se expresa en la tabla 1.

Para llevar a cabo la investigación nos hemos valido de los siguientes instrumentos:

- Un cuestionario de variables socioeducativas, que consideramos que pueden tener relación con los procesos de reeducación.

- Un cuestionario de actitudes.

- Una escala de sinceridad.

A continuación analizamos cada uno de estos instrumentos.

\subsection{Escala de sinceridad}

La exponemos en primer lugar porque esto facilita el posterior desarrollo de la exposición de la investigación.

Introducimos esta escala por necesidad metodológica, para así evitar que nuestra investigación se desvirtúe por respuestas poco sinceras. Utilizamos la escala propuesta por Pinillos (1990) (Figura 1). Esta escala está constituida por una serie de ítems referidos a cuestiones relativas a pequeñas faltas morales o sociales frecuentes, pero cuya confesión pública puede ser embarazosa.

Una vez recogidas las respuestas de los cuestionarios, abordamos el análisis de los
FIGURA 1. DISTRIBUCIÓN DE PUNTUACIONES EN SINCERIDAD

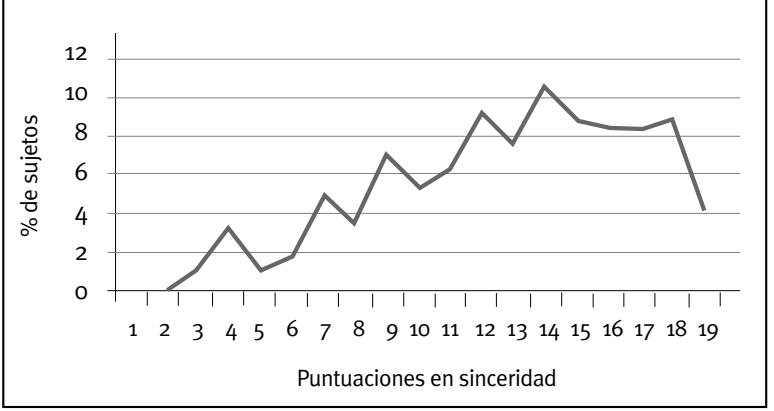

mismos con el programa estadístico SPSS (Statistiakal Package for Social Sciences), versión 11.5 .

Con objeto de establecer un punto de corte que permita distinguir a los jóvenes que son más sinceros de los que lo son menos, se ha obtenido el percentil 25, cuyo valor nos da una puntuación de 10; el percentil 50, cuyo valor es 13 y el percentil 75, cuyo valor es 16 .

A partir de estos valores procedemos a eliminar los casos que se encuentran por debajo del percentil 25, por considerar que estos jóvenes han sido poco sinceros en sus respuestas, quedando el número de casos reducido a 206 sujetos, que podemos considerar que han sido más sinceros en sus respuestas. Observamos que el $27,7 \%$ de los jóvenes han sido poco sinceros en sus respuestas. 
De estos 206 sujetos, 196 son hombres y 10 son mujeres. Son españoles el 70,5\%, estableciéndose la edad media en 19 años.

\subsection{Variables socioeducativas}

Hemos seleccionado 42 variables que consideramos que de alguna manera pueden estar relacionadas con la reeducación y con ellas pretendemos conocer tanto las singularidades de los jóvenes como las características del grupo.

Estas variables socioeducativas las agrupamos en cuatro ámbitos de estudio:

- Nivel escolar y cualificación profesional, donde se recogen datos relativos a la edad, nivel académico, formación y experiencia laboral, etc.

- Relaciones familiares, donde se recoge información sobre los estudios de los padres y madres, las profesiones paternas y maternas, si existen o no antecedentes familiares en prisión, etc.

- Contactos con la marginalidad, recogiendo datos relativos a consumos de drogas, primeros consumos, tipos de drogas consumidas, primer delito cometido, delitos posteriores, influencias recibidas para delinquir, ingresos en centros de menores, etc.

- Vida en prisión, con la que pretendemos conocer su itinerario en el interior del centro penitenciario, recogiendo datos relativos a la situación penal, si están en situación de penados o de preventivos, a la espera de juicio; situación penitenciaria, si son primarios o reincidentes, con más de un ingreso en prisión; actividad que realiza en prisión, si estudia, trabaja, en qué ocupa el tiempo libre, etc.

\subsection{Cuestionario de actitudes}

Elaboramos un cuestionario de tipo Likert en el que los jóvenes debían posicionarse "muy de acuerdo", "de acuerdo", "indiferente",

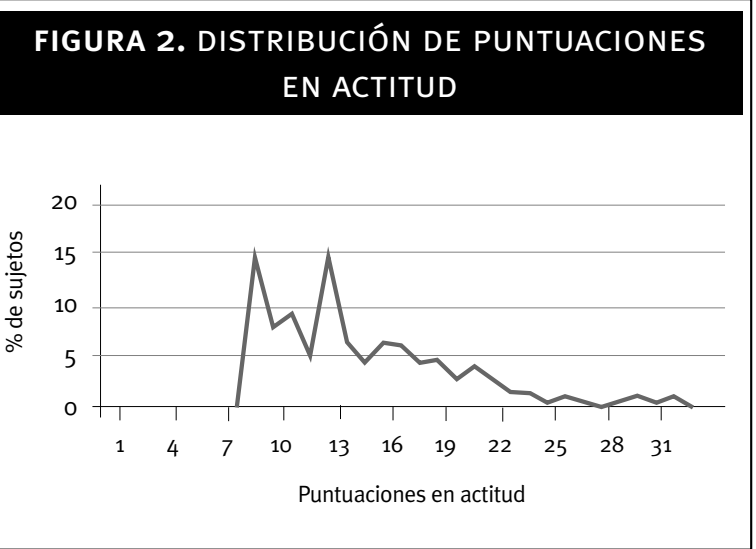

"en desacuerdo", "muy en desacuerdo" con lo expresado en cada uno de los 18 ítems que componen el cuestionario.

Una vez obtenidos los datos, realizamos un análisis de componentes principales, y una depuración en tres fases, llegando a un análisis factorial en el que algunos ítems tienen una saturación inferior a 0,30 en un factor o saturan en más de un factor. Procedemos a eliminar estos ítems y obtenemos una solución en un factor que explica el 34,6\% de la varianza.

De los 18 ítems de los que partíamos, seleccionamos 9 ítems que constituyen el cuestionario definitivo y que muestran las actitudes de los jóvenes menores de 21 años de las prisiones andaluzas ante los procesos de reeducación. Esta escala es sometida a un análisis de fiabilidad, presentando homogeneidad y coherencia. Existen ítems formulados de manera favorable y otros de manera desfavorable, para evitar el sesgo de aquiescencia.

Consideramos que a mayor puntuación obtenida en esta escala corresponde mejor actitud ante la reeducación.

La puntuación mínima es de 9, la máxima es de 32, estableciéndose la media en 14,85. Consideramos que la población situada por debajo de la media tiene actitud baja. En este caso, 127 sujetos que se corresponden con el $62 \%$ del total. Las puntuaciones, frecuencias y porcentajes obtenidos se presentan en la tabla 2, así como en la figura 2. 
TABLA 2. PUNTUACIONES, PORCENTAJES $Y$ FRECUENCIAS DEL CUESTIONARIO DE ACTITUDES

$\begin{array}{lll}\text { Puntuaciones } & \text { Frecuencia } & \text { Porcentaje (\%) }\end{array}$

9

10

10

11

12

30

16

19

10

4,9

13

14

15

16

17

8

18

19

20

21

22

$22-2$

23

24

25

26

27

29

2

1

206

$100 \%$

Por lo tanto, podemos considerar que el 38\% de los jóvenes estudiados mantienen una actitud alta ante los procesos de reeducación, o al menos, se sitúan por encima de la media.

Una vez establecido este dato, nos interesaba conocer qué variables socioeducativas se encuentran relacionadas con la actitud, para lo que procedemos a estudiar las relaciones existentes a través de un estudio del chi-cuadrado. Así, podemos observar que las variables socioeducativas que de alguna manera se relacionan con la actitud son:

- El nivel académico de los padres.

- Ingresos en centros de menores.

- La situación penitenciaria, es decir, ser primario, con un solo ingreso en prisión, o ser reincidente, con más de un ingreso.

- Participación en Talleres Ocupacionales.

- Participación en Talleres Productivos.

- Participación en Cursos Formativos.

- Sentirse valorado por la actividad que realizan en prisión.

- Influencias para delinquir del entorno social.

- Motivo del primer delito.

Estas variables las podemos agrupar en cuatro núcleos de estudio:

- Ámbito familiar:

Nivel de estudios del padre.

- Ámbito de lo emocional:

Sentirse valorado por la actividad que realiza en prisión.

- Ámbito de la prevención delictiva:

Situación penitenciaria: primarios.

Influencias para delinquir del entorno social.

Motivos del primer delito: comprar drogas.

Haber estado ingresado en centros de menores.

- Ámbito de lo formativo:

Participar en talleres ocupacionales.

Participar en talleres productivos.

Participar en cursos formativos. 


\section{Interpretación y conclusiones}

De este modo, para que sea probable predecir una evolución de una actitud baja a una actitud alta en el ámbito de la reeducación en los centros penitenciarios andaluces, es necesario trabajar los ámbitos de lo familiar, de lo emocional, de la prevención delictiva y de lo formativo.

Así, trabajando estos ámbitos de manera adecuada podemos llegar a tener un cambio de actitudes en los jóvenes que se encuentran en nuestros centros penitenciarios.

En definitiva, observamos que los jóvenes internados en prisión menores de veintiún años, mantienen una actitud alta ante los procesos de reeducación si su situación penitenciaria es de primario, delinquió por influencias del entorno social, cometió su primer delito para comprar drogas, no ha estado ingresado en centros de menores, participa en talleres ocupacionales, participa en talleres productivos, participa en cursos formativos, se siente valorado por la actividad que realiza, siendo el nivel académico de los padres de bachiller o universitario.

Algunas de estas variables no son controlables desde la Institución Penitenciaria, como pueden ser la situación de primario, cometer el delito por influencias de la sociedad, cometer el primer delito para comprar drogas, no haber estado ingresado en centros de menores o el nivel académico de los padres.

Pero desde las prisiones, y concretamente desde el puesto de educador, si está en nuestras manos trabajar para que los jóvenes internados en prisión participen en talleres ocupacionales, talleres productivos, cursos formativos y se sientan valorados por la actividad que realizan en prisión, porque estas variables sí parecen fundamentales para que los jóvenes internados tengan una actitud alta ante los procesos de reeducación.

Asimismo, desde los centros penitenciarios debemos trabajar para conseguir que lo académico, la ocupación del tiempo de ocio con actividades deportivas o el trabajo, a todas luces variables importantísimas para la vida de los jóvenes en prisión, adquieran la importancia debida, para que propicien una actitud adecuada hacia la reeducación.

En cualquier caso, los ámbitos de lo familiar, lo formativo, lo emocional y lo preventivo, constituyen aspectos a trabajar tanto para que se consigan actitudes positivas hacia la reeducación, como para conseguir mejoras en las actitudes ante la reeducación en el ámbito penitenciario. Una vez establecidas las relaciones entre las variables socioeducativas y la actitud, tratamos de averiguar qué variables socioeducativas influyen sobre la actitud ante la reeducación.

Para ello realizamos un análisis de regresión logística univariante y un análisis de regresión logística multivariante, interpretando odds ratio, entendidas como la razón entre la posibilidad de que ocurra un suceso y la posibilidad de que no ocurra, es decir, se trata de un número que expresa cuánto más probable es que se produzca un hecho, frente a que no se produzca (Silva y Barroso: 2004, 13). En nuestro caso, cuanto más probable es que se produzca actitud alta cuando esté presente alguna de las variables socioeducativas con las que hemos trabajado. El número de referencia es la unidad y cuanto más nos alejamos de ella positivamente, aumentará la probabilidad de que se produzca el hecho. Si el número se encuentra por debajo de la unidad, tomamos la variable socioeducativa en sentido contrario.

Las variables que han resultado ser estadísticamente significativas, $\mathrm{p}<0,05$, en los análisis de regresión logística univariante, las utilizamos para construir un modelo de regresión logística multivariante, considerando como variable dependiente la actitud baja/alta.

En los análisis de regresión logística univariante y multivariante utilizamos el test de bondad del ajuste basado en el estadístico ratio de verosimilitud chi-cuadrado, por tratarse de muestras de tamaño pequeño (Kleinbaum: 1994, 135). 
TABLA 3. VARIABLES QUE FORMAN PARTE DEL MODELO DE RLM

\begin{tabular}{|c|c|c|c|c|c|c|}
\hline Variables & B & ET & WALD & GI & $\mathbf{p}$ & OR \\
\hline Ingresos en centros de menores & $-0,745$ & 0,395 & 5,070 & 1 & 0,02 & 0,47 \\
\hline Sentirse valorado en prisión & 1,122 & 0,344 & 10,626 & 1 & 0,00 & 3,07 \\
\hline Primer delito para comprar drogas & $-1,549$ & 0,395 & 6,419 & 1 & 0,01 & 5,44 \\
\hline Participa en taller productivo & 1,262 & 0,652 & 3,747 & 1 & 0,05 & 3,53 \\
\hline Constante & 0,427 & 0,351 & 14,992 & 1 & 0,00 & 0,32 \\
\hline
\end{tabular}

Como decíamos, a partir de las variables socioeducativas seleccionadas realizamos un análisis de regresión logística multivariante con la finalidad de determinar las variables socioeducativas que simultáneamente predicen una actitud alta ante la reeducación. Estas variables son:

- No haber estado ingresado en centros de menores.

- Sentirse valorado por la actividad que realiza en prisión.

- Cometió el primer delito para comprar drogas.

- Durante su estancia en prisión, participa en talleres productivos.

Por lo tanto, podemos decir que los valores de las odds ratio indican que tener actitud alta ante la reeducación es más probable en los jóvenes internados en prisiones andaluzas que no han estado con anterioridad ingresados en centros de menores, que se sienten valorados por la actividad que realizan en prisión, que cometieron el primer delito para comprar drogas y que durante su estancia en prisión participan en talleres productivos.

\section{A modo de reflexión final}

En definitiva, los internos mayoritariamente perciben de manera negativa los ítems que prestigian la función reeducadora de la Institución Penitenciaria. Asimismo, perciben de forma negativa su propia actitud ante los procesos de reeducación. Mientras que valoran de manera positiva la realización de actividades durante su estancia en prisión, aunque consideran que no les ayudan en su reeducación, ni que la organización de los centros penitenciarios permita realizarlas adecuadamente. Del mismo modo, perciben mayoritariamente que la prisión no mejorará su futuro ni los prepara para la vida en libertad.

En cualquier caso, debemos cuestionarnos la viabilidad de los centros penitenciarios como lugares de reeducación, porque parece evidente que para reeducar, educar, en definitiva, es necesario un ambiente de libertad, y desde el encierro de un centro penitenciario parece improbable acometer procesos de reeducación. Parece improbable acometer procesos de reinserción social, inserción social, inclusión, separando con un muro, segregando a la población que pretendemos reinsertar, ya que para reinsertar, insertar, necesitamos del contacto de la sociedad con las personas aisladas. Estos procesos desde un centro penitenciario parecen de difícil ejecución.

Creemos, sin embargo, en el componente pedagógico y educativo que debe presidir las actuaciones en los centros penitenciarios, y que deben llevar aparejada la consecución de la normalización de la conducta de los internados, a través de los valores morales y éticos de una sociedad democrática.

Así, y aun considerando simplista la explicación de que los problemas de margina- 
ción, exclusión social, inadaptación y delincuencia, son únicamente debidos a déficits educativos, pensamos que desde la pedagogía social y con un enfoque educativo, sí se pueden aportar soluciones que palien estos estados carenciales.

Parece necesario la intervención desde la pedagogía social, y desde este ámbito debemos estudiar y diseñar intervenciones que favorezcan formas de convivencia más justas, solidarias y libres, y menos violentas, excluyentes e insolidarias, no por mera solidaridad, sino por motivos de justicia social.

No cabe duda que estos planteamientos quedan lejos de las condiciones de vida de un centro penitenciario, pero no por ello debemos renunciar a su implantación, porque el discurso pedagógico tiene que ser, por naturaleza, potencialmente utópico, ya que, como nos indica el profesor Sáez (2003), esto nos permite cargar de valores e ideales nuestras intervenciones.

Optamos por la conversión de la Institución Penitenciaria en una institución educativa donde se implante un modelo pedagógico con una intervención más humana.

Consideramos que el ingreso en prisión de personas, es el último argumento al que debemos recurrir para resolver nuestros problemas sociales, ya que como nos indica Javier Urra (1997), con el ingreso en prisión se evita el mal, pero no se proporciona el bien.

Creemos que debemos intervenir con actuaciones pedagógicas encaminadas a la prevención de la reincidencia, respetando escrupulosamente los derechos humanos de los internados, a través de una educación en la ciudadanía y en los valores democráticos, con intervenciones pedagógicas hacia la reeducación.

\section{Referencias bibliográficas}

Amorós, P. y Ayerbe, P. (Eds.) (2000): Intervención educativa en inadaptación social. Madrid: Síntesis.

Beristain, A. (1985): Ciencia penal y criminología. Madrid: Tecnos.
Bolívar, A. (1995): La evaluación de valores y actitudes. Madrid: Anaya.

Constitución Española de 31 de octubre de 1978. (B.O.E. $n^{\circ}$. 311, de 29 de diciembre).

Escámez, J.y Ortega, P. (1986): La enseñanza de actitudes y valores. Valencia: Nau Llibres.

Foucault, M. (1976): Vigilar y castigar. México: Siglo XXI.

García, J. y Sancha, V. (1986): Psicología penitenciaria. Áreas de intervención terapéutica. Madrid: UNED.

Hair, J; Anderson, R.; Tatham, R. y Black, W. (1999): Análisis multivariante. Madrid: Prentice Hall Iberia.

Kaiser, G. (1988): Introducción a la criminología. Madrid: Dykinson.

Kleinbaum, D.G. (1994): Logistic Regresion. New York: Springer Verlag.

Martín Solbes, V.M. (2006): Actitudes de los internados en prisión, menores de veintiún años, ante la función reeducadora del medio penitenciario en el ámbito andaluz. Málaga: Servicio de Publicaciones de la Universidad de Málaga

Martínez, R. (1999): El análisis multivariante en la investigación científica. Salamanca: Hespérides.

Sáez, J. (2003): La profesionalización de los educadores sociales. En busca de la competencia educativa cualificadora. Madrid: Dykinson.

Silva, L.C. y Barroso, I.Ma. (2004): Regresión Logística. Cuadernos de Estadística, $n^{\circ}$ 27. Salamanca: Hespérides.

Urra, J. (1997): Violencia. Memoria amarga. Madrid: Siglo XXI.

DIRECCIÓN DEL AUTOR: Víctor Manuel Martín Solbes. Facultad de Ciencias de la Educación. Departamento de Teoría e Historia de la Educación. Universidad de Málaga Campus de Teatinos, s/n. 29071. Málaga. Correo electrónico: victorsolbes@uma.es

Fecha de recepción del artículo: 23.VII.2008 Fecha de aceptación del artículo: 3.XII.2008 